GRENZE

\title{
A Novel MO-DXCCII based CMQO Operated at Low Voltage
}

\author{
Atul Kumar ${ }^{1}$ and Bhartendu Chaturvedi ${ }^{2}$ \\ ${ }^{1-2}$ Department of Electronics and Communication Engineering, Jaypee Institute of Information Technology \\ Noida, U.P., 201304, India \\ atul.nit304@gmail.com, bhartendu.prof@gmail.com
}

\begin{abstract}
In this paper, a new current-mode quadrature oscillator (CMQO) is proposed using two grounded capacitors and two resistors along with two multi-output dual-X second generation current conveyors (MO-DXCCII). The proposed circuit provides three current outputs simultaneously with high output impedances. The circuit of proposed quadrature oscillator also enjoys the low active and passive sensitivities. The new circuit is suited for high frequency and low operating voltage operation also. The proposed circuit is also made resistorless by using MOS based active resistors. HSPICE simulation results are given to confirm the theory.
\end{abstract}

Index Terms - Current-mode; Quadrature oscillator; DXCCII; Analog signal processing.

\section{INTRODUCTION}

In integrated circuits, current-mode circuits offer several advantages over voltage-mode circuits such as large bandwidth, simple circuitry, wider dynamic range, high speed and very low power consumption [1]. A CMQO provides two sinusoid currents with $90^{\circ}$ phase difference and it is widely used in a large number of applications such as in communication, power electronics, measurement and instrumentation systems and signal processing. As a result, the technical literature is very well filled by a number of circuits of CMQO realized using different types of active elements such as current-controlled current conveyor (CCCII) [2-4], differential voltage current conveyor (DVCC) [5-6], current differencing transconductance amplifier (CDTA) [7-10], current differencing buffered amplifier (CDBA) [11], current conveyor transconductance amplifier (CCTA) [12], current controlled current conveyor transconductance amplifier (CCCCTA) [13-14] and current controlled current differencing transconductance amplifier (CCCDTA) [15-16]. Third order CMQOs are reported in [2, 3 and 9]. The all-pass filter is cascaded with integrator to obtain the quadrature oscillator circuit in [7, 8 and 16], while in [8] two all-pass filters are cascaded to obtain the quadrature oscillator. The circuits reported in $[7,8,12,13,15$ and 16] offer the advantages of high impedance outputs. A current-mode circuit with high output impedance cab be easily cascaded. The frequency of oscillation and condition of oscillation in [7, 12, 13, 15 and 16] can be controlled independently.

In this paper, a new CMQO based on MO-DXCCII is presented. A dual-X second generation current conveyor (DX-CCII) is a versatile element, which has a large number of applications in analog signal processing [17-22]. The proposed circuit employs two MO-DXCCIIs, two grounded capacitors and two resistors. The proposed quadrature oscillator is derived from the all-pass filter [19]. A RC integrator is

Grenze ID: 01.GIJET.2.2.26

(C) Grenze Scientific Society, 2016 
connected in cascade with the all-pass filter to obtain the proposed quadrature oscillator. The non-ideal and parasitic study of the proposed circuit is also performed. The proposed circuit offers the following advantages: (i) three current outputs simultaneously, (ii) low active and passive sensitivities, (iii) high output impedances, (iv) total harmonic distortion of each output is low, (v) operated at low voltage, (vi) high frequency of oscillation and (vii) resistorless realization. HSPICE simulation results are given to validate the performance of the proposed circuit. This paper is arranged as follows: the details of proposed CMQO along with non-ideal and parasitic analysis are given in section 2. HSPICE simulation results are given in section 3. The resistorless realization of proposed circuit is given in section 4. Finally, section 5 contains the concluding remarks.

\section{PROPOSED CIRCUIT}

A DX-CCII [20] was first introduced by A. Zeki and A. Toker. It combines the characteristics of both the second generation current conveyor and inverting second generation current conveyor. "Fig. 1," shows the CMOS implementation of MO-DXCCII. The port relationship of MO-DXCCII can be specified as

$$
\left[\begin{array}{c}
I_{Y} \\
V_{X+} \\
V_{X-} \\
I_{Z 1+} \\
I_{Z 2+} \\
I_{Z 1-} \\
I_{Z 2-}
\end{array}\right]=\left[\begin{array}{ccc}
0 & 0 & 0 \\
1 & 0 & 0 \\
-1 & 0 & 0 \\
0 & 1 & 0 \\
0 & 1 & 0 \\
0 & 0 & 1 \\
0 & 0 & 1
\end{array}\right]\left[\begin{array}{c}
V_{Y} \\
I_{X+} \\
I_{X-}
\end{array}\right]
$$

The proposed circuit of CMQO is shown in "Fig. 2,". It is composed of two MO-DXCCIIs, two grounded capacitors and two resistors. The characteristic equation of the circuit is given as below

$$
s^{2}+s \frac{\left(R_{2} C_{2}-R_{1} C_{1}\right)}{R_{1} R_{2} C_{1} C_{2}}+\frac{1}{R_{1} R_{2} C_{1} C_{2}}=0
$$

The oscillation frequency (FO) and oscillation condition (CO) can be obtained as

$$
\begin{aligned}
& \text { FO: } f_{0}=\frac{1}{2 \pi \sqrt{R_{1} R_{2} C_{1} C_{2}}} \\
& \text { CO: } R_{2} C_{2} \leq R_{1} C_{1}
\end{aligned}
$$

The various current outputs shown in "Fig. 3," are related as

$$
I_{1}=j \omega R_{2} C_{2} I_{3}, \quad I_{2}=-I_{3}
$$

The sensitivities of FO with respect to passive components can be given as

$$
S_{C_{1}, C_{2}, R_{1}, R_{2}}^{f_{0}}=-\frac{1}{2}
$$

It is to be observed from "(6)" that all the passive sensitivities are less than unity in magnitude.

\section{A. Non-ideal analysis}

By considering the non-idealities of MO-DXCCII, the relationship between voltages and currents at different ports of MO-DXCCII can be written as

$$
V_{X+}=\beta_{1 i} V_{Y}, V_{X-}=\beta_{2 i} V_{Y}, I_{Z 1+}=\alpha_{1 i} I_{X+},
$$




$$
I_{Z 2+}=\alpha_{2 i} I_{X+}, I_{Z 1-}=\alpha_{3 i} I_{X-} \text { and } I_{Z 2-}=\alpha_{4 i} I_{X-}
$$

Here, $\beta_{1 \mathrm{i}}$ and $\beta_{2 \mathrm{i}}$ are voltage transfer gains from $Y$ terminal to $\mathrm{X}+$ and $\mathrm{X}$ - terminals, respectively $\alpha_{1 \mathrm{i}}$ and $\alpha_{2 \mathrm{i}}$ are current transfer gains from $X+$ terminal to $Z_{1+}$ and $Z_{2+}$ terminals, respectively and $\alpha_{3 \mathrm{i}}$ and $\alpha_{4 \mathrm{i}}$ are current transfer gains from $\mathrm{X}$ - terminal to $\mathrm{Z}_{1}$ - and $\mathrm{Z}_{2}$ - terminals, respectively with $\mathrm{i}=1$ corresponding to $\mathrm{MO}$ DXCCII (1) and $\mathrm{i}=2$ corresponding to MO-DXCCII (2).

The proposed circuit is reanalyzed assuming the non-ideal MO-DXCCII; the modified characteristic equation is found as

$$
s^{2}+s \frac{\left(R_{2} C_{2}-\alpha_{41} \alpha_{32} \alpha_{12} \beta_{12} R_{1} C_{1}\right)}{R_{1} R_{2} C_{1} C_{2}}+\frac{\alpha_{32} \alpha_{12} \beta_{12}\left(\alpha_{11} \alpha_{31}+\alpha_{21} \alpha_{31}-\alpha_{41}\right)}{R_{1} R_{2} C_{1} C_{2}}=0
$$

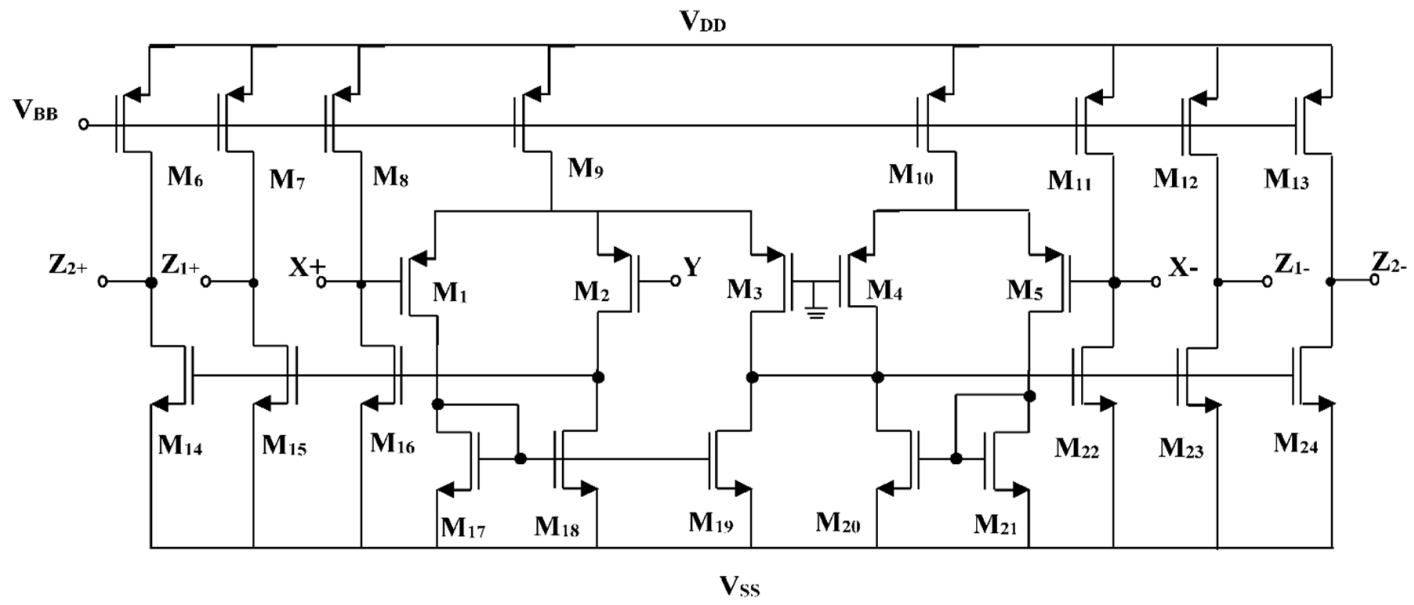

Figure1. The CMOS implementation of MO-DXCCII

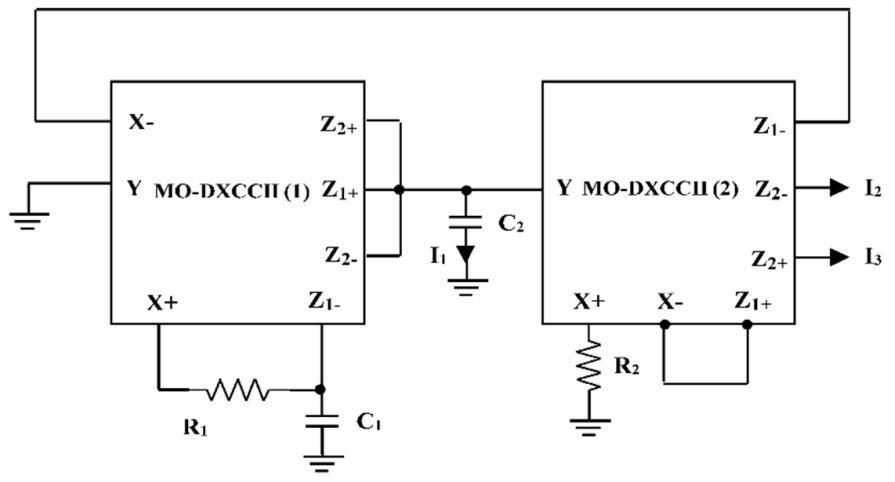

Figure2. Proposed circuit of CMQO

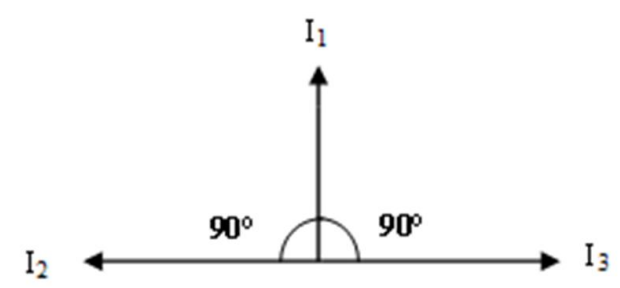

Figure3. Phasor diagram showing quadrature current outputs 
The modified FO and $\mathrm{CO}$ can be given as

$$
\text { FO: } f_{0}=\frac{1}{2 \pi} \sqrt{\frac{\alpha_{32} \alpha_{12} \beta_{12}\left(\alpha_{11} \alpha_{31}+\alpha_{21} \alpha_{31}-\alpha_{41}\right)}{R_{1} R_{2} C_{1} C_{2}}}
$$

CO: $R_{2} C_{2} \leq \alpha_{41} \alpha_{32} \alpha_{12} \beta_{12} R_{1} C_{1}$

The sensitivities of FO with respect to active and passive components can be found as

$$
\begin{gathered}
S_{\alpha_{32}, \alpha_{12}, \beta_{12}}^{f_{0}}=\frac{1}{2} \\
S_{\alpha_{11}}^{f_{0}}=\frac{\alpha_{11} \alpha_{31}}{\alpha_{11} \alpha_{31}+\alpha_{21} \alpha_{31}-\alpha_{41}} \\
S_{\alpha_{31}}^{f_{0}}=\frac{\alpha_{31}\left(\alpha_{11}+\alpha_{21}\right)}{\alpha_{11} \alpha_{31}+\alpha_{21} \alpha_{31}-\alpha_{41}} \\
S_{\alpha_{21}}^{f_{0}}=\frac{\alpha_{21} \alpha_{31}}{\alpha_{11} \alpha_{31}+\alpha_{21} \alpha_{31}-\alpha_{41}} \\
S_{\alpha_{41}}^{f_{0}}=\frac{-\alpha_{41}}{\alpha_{11} \alpha_{31}+\alpha_{21} \alpha_{31}-\alpha_{41}} \\
S_{C_{1}, C_{2}, R_{1}, R_{2}}^{f_{0}}=-\frac{1}{2}
\end{gathered}
$$

Equations (11) to (16) shows that the sensitivity figures for FO are all within unity in magnitude, which implies good sensitivity performance of the circuit.

\section{B. Parasitic Effects}

A parasitic model of MO-DXCCII is shown in "Fig. 4,". The parasitic study of MO-DXCCII involves parasitic resistances $\mathrm{R}_{\mathrm{X}+}$ and $\mathrm{R}_{\mathrm{X}-}$ at $\mathrm{X}+$ and $\mathrm{X}$ - terminals respectively, a parallel combination $\left(\mathrm{R}_{\mathrm{Y}} / / \mathrm{C}_{\mathrm{Y}}\right)$ at $\mathrm{Y}$ terminal and parasitic at $\mathrm{Z}_{1+}, \mathrm{Z}_{2+}, \mathrm{Z}_{1 \text { - }}$ and $\mathrm{Z}_{2 \text { - }}$ terminals are $\left(\mathrm{R}_{\mathrm{Z} 1+} / / \mathrm{C}_{\mathrm{Z1} 1+}\right),\left(\mathrm{R}_{\mathrm{Z}_{2}+} / / \mathrm{C}_{\mathrm{Z} 2+}\right),\left(\mathrm{R}_{\mathrm{Z1} 1} / / \mathrm{C}_{\mathrm{Z1} 1}\right)$ and $\left(\mathrm{R}_{\mathrm{Z}_{2}-} / /\right.$ $\mathrm{C}_{\mathrm{Z2}-}$ ), respectively [20]. The effects of parasitic capacitance at $\mathrm{Y}$ and $\mathrm{Z}$ ports of MO-DXCCII are negligible as these capacitors are quite small as compared to external capacitors. The parasitic resistances at $\mathrm{X}+$ terminals of both MO-DXCCIIs can be merged with external resistors, because X+ terminals of both MODXCCIIs are connected to external resistors. There will be a little deviation in FO of proposed circuit due to these parasitic which can be minimized by pre-warping the component values used in circuit. However, a reanalysis of the proposed circuit of quadrature oscillator is done which yields the following characteristic equation

$$
s^{2}+s \frac{A}{R_{1}^{\prime} R_{2}^{\prime} C_{1}^{\prime} C_{2}^{\prime}}+\frac{B}{R_{1}^{\prime} R_{2}^{\prime} C_{1}^{\prime} C_{2}^{\prime}}=0
$$

where, $A=R_{2}^{\prime} C_{2}^{\prime}\left(1+\frac{R_{1}^{\prime}}{R_{Z 1-}}\right)-R_{1}^{\prime} C_{1}^{\prime}+\frac{R_{1}^{\prime} R_{2}^{\prime} C_{1}^{\prime}}{R^{\prime}}$ and $B=\frac{R_{2}^{\prime}}{R^{\prime}}\left(\frac{R_{1}^{\prime}}{R_{Z 1-}}+1\right)-\left(\frac{R_{1}^{\prime}}{R_{Z 1-}}-1\right)$,

where, $R^{\prime}=R_{Y 2} / / R_{Z 11_{+}} / / R_{Z 21+} / / R_{Z 21-}, R_{1}^{\prime}=R_{1}+R_{X 1+}, R_{2}^{\prime}=R_{2}+R_{X 2+}, C_{1}^{\prime}=C_{1}+C_{Z 11_{-}}$and $C_{2}^{\prime}=C_{2}+C_{Y 2}+C_{Z 11+}+C_{Z 21+}+C_{Z 21-}$. 


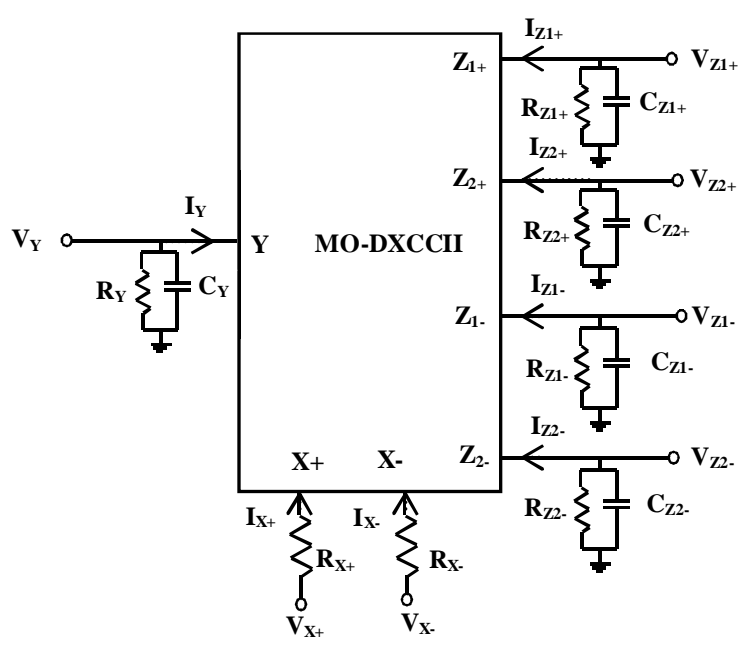

Figure4. Parasitic model of MO-DXCCII

\section{Simulation RESUltS}

The proposed circuit of CMQO is simulated using HSPICE with $0.18 \mu \mathrm{m}$ TSMC CMOS process parameters. The supply voltages used were $\mathrm{V}_{\mathrm{DD}}=-\mathrm{V}_{\mathrm{SS}}=1.25 \mathrm{~V}$ and biasing voltage was $\mathrm{V}_{\mathrm{BB}}=0.3 \mathrm{~V}$. The values of external components used in circuit was $\mathrm{C}_{1}=\mathrm{C}_{2}=1 \mathrm{pF}, \mathrm{R}_{1}=2 \mathrm{~K} \Omega$ and $\mathrm{R}_{2}=1.59 \mathrm{~K} \Omega$. The theoretical FO for these values of external components was $89.25 \mathrm{MHz}$. The simulation results for the three current outputs are shown in Fig. 5. The simulated FO was found to be $93 \mathrm{MHz}$. The simulated FO deviates from theoretical FO because of the non-ideal and parasitic effects described in section 2. The total harmonic distortion (THD) of each output is found with-in 1.4\%. "Fig. 6," shows the simulated Fourier spectrum of output currents. In addition, to confirm the $90^{\circ}$ phase difference between the current outputs, the lissajous patterns are given in "Fig. 7," and "Fig. 8,". The usefulness of new circuit is to be especially emphasized keeping in view the design frequency which is quite high.

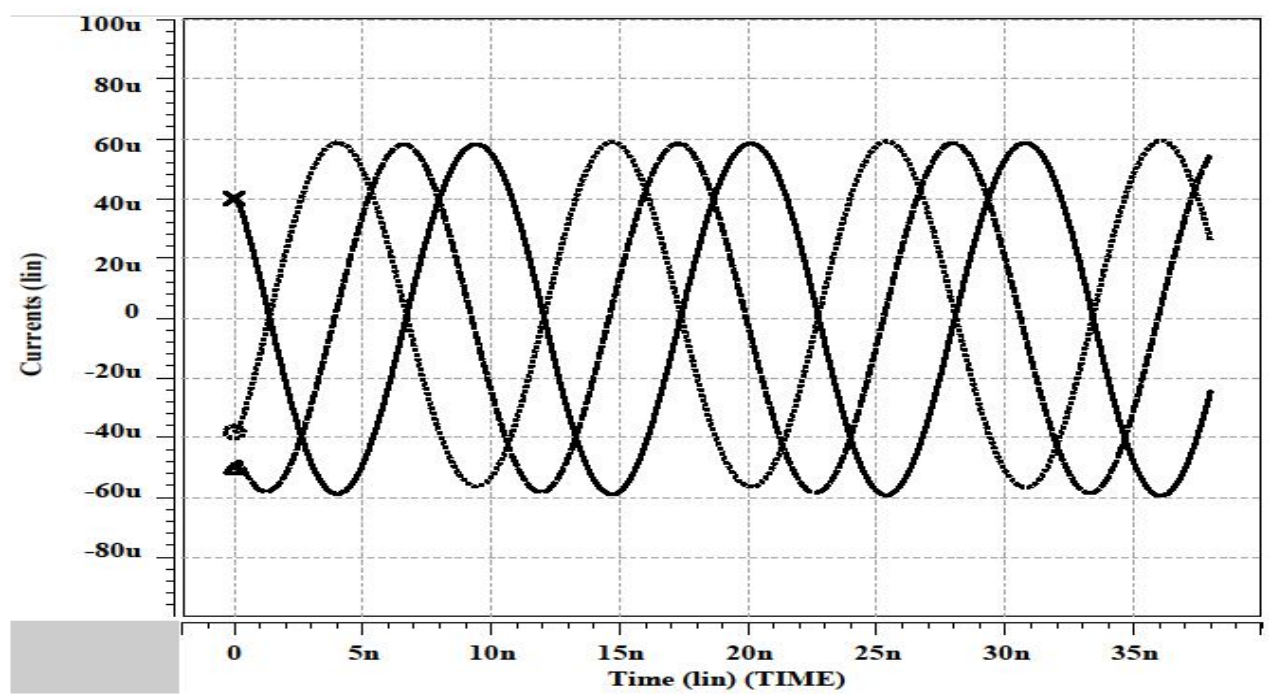

Figure5. Quadrature current output waveforms 


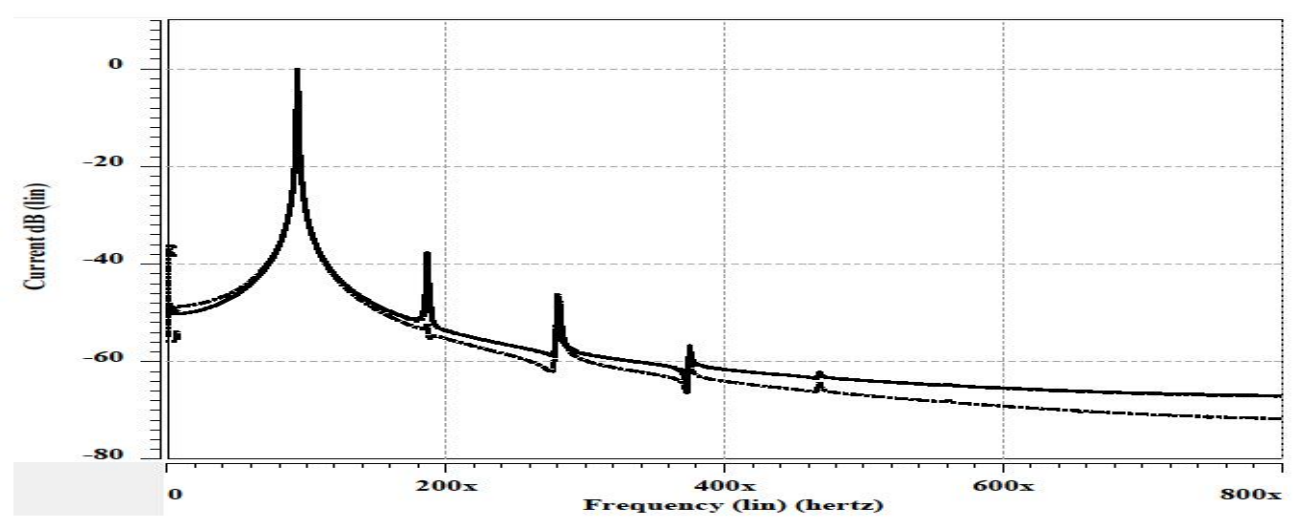

Figure6. Frequency spectrum of current outputs

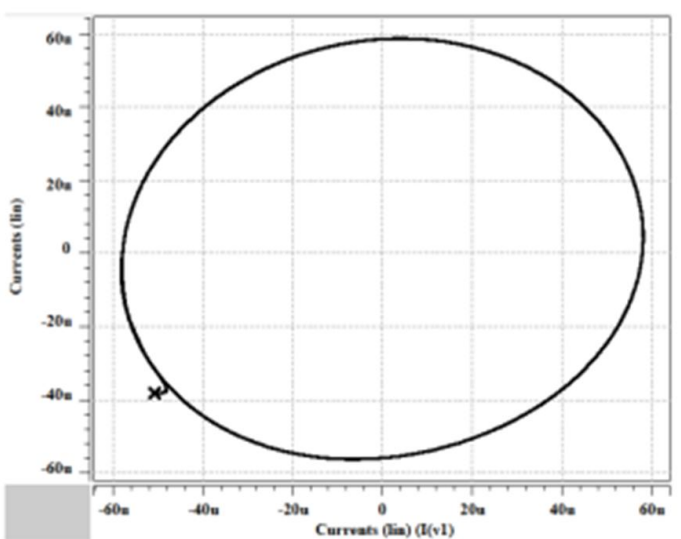

Figure7. Lissajous pattern showing $90^{\circ}$ phase difference between output currents $\left(\mathrm{I}_{1}\right.$ and $\left.\mathrm{I}_{2}\right)$

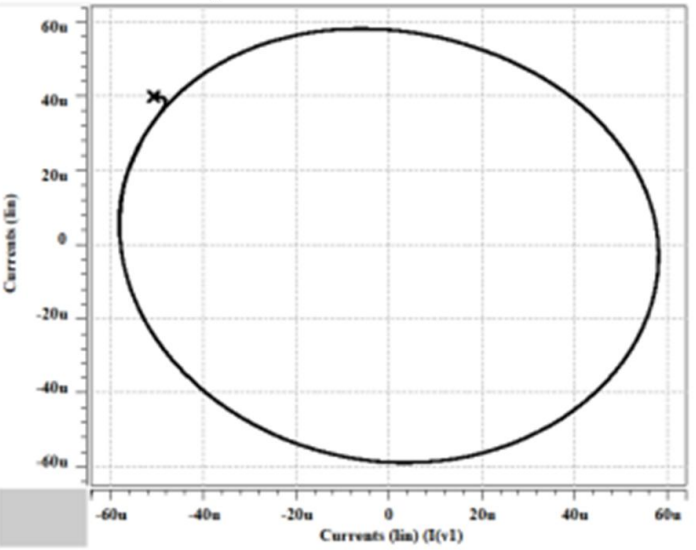

Figure8. Lissajous pattern showing $90^{\circ}$ phase difference between output currents $\left(\mathrm{I}_{1}\right.$ and $\left.\mathrm{I}_{3}\right)$

\section{RESISTORLESS REALIZATION OF PROPOSED CIRCUIT}

The proposed circuit was made resistorless by using a single n-MOS transistor biased in triode region in place of floating resistor $\left(\mathrm{R}_{1}\right)$, and two n-MOS transistor based grounded resistor in place of grounded resistor $\left(\mathrm{R}_{2}\right)$ [23]. A possible realization of resistorless CMQO is shown in "Fig. 9,". The characteristic equation of the proposed resistorless circuit is given as below

$$
s^{2}+s \frac{\left(R_{M{ }_{2}} C_{2}-R_{M 1} C_{1}\right)}{R_{M 1} R_{M{ }_{2}} C_{1} C_{2}}+\frac{1}{R_{M 1} R_{M{ }_{2}} C_{1} C_{2}}=0
$$

where, $R_{M 1}$ and $R_{M 2}$ are the equivalent resistances of $n-M O S$ transistor $M_{R 3}$, and n-MOS transistors $M_{R 1}$ and $M_{R 2}$ respectively in Fig. 9 and expressions of $R_{M 1}$ and $R_{M 2}$ are given as

$$
\begin{aligned}
& R_{M 1}=\left[\mu C_{O X}\left(\frac{W}{L}\right)\left(V_{C 2}-V_{T}\right)\right]^{-1} \\
& R_{M 2}=\left[2 \mu C_{O X}\left(\frac{W}{L}\right)\left(V_{C 1}-V_{T}\right)\right]^{-1}
\end{aligned}
$$


The FO and $\mathrm{CO}$ of resistorless circuit can be obtained as

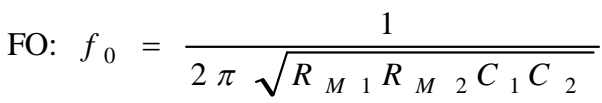

$$
\begin{aligned}
& \mathrm{CO}: R_{M}{ }_{2} C_{2} \leq R_{M{ }_{1}} C_{1}
\end{aligned}
$$

The resistorless circuit was simulated by taking the aspect ratios $(\mathrm{W} / \mathrm{L})_{\mathrm{MR} 1}=(\mathrm{W} / \mathrm{L})_{\mathrm{MR} 2}=0.45 \mu \mathrm{m} / 0.18 \mu \mathrm{m}$, $(\mathrm{W} / \mathrm{L})_{\mathrm{MR} 3}=0.36 \mu \mathrm{m} / 0.18 \mu \mathrm{m}$ and capacitors values were selected as $\mathrm{C}_{1}=\mathrm{C}_{2}=1 \mathrm{pF}$. The FO of resistorless circuit is tuned to $88 \mathrm{MHz}$ when controlling voltage were selected as $\mathrm{V}_{\mathrm{C} 1}=1.1 \mathrm{~V}$ and $\mathrm{V}_{\mathrm{C} 2}=1.059 \mathrm{~V}$. The three current outputs and their Fourier spectrums are shown in "Fig. 10", and "Fig. 11," respectively.

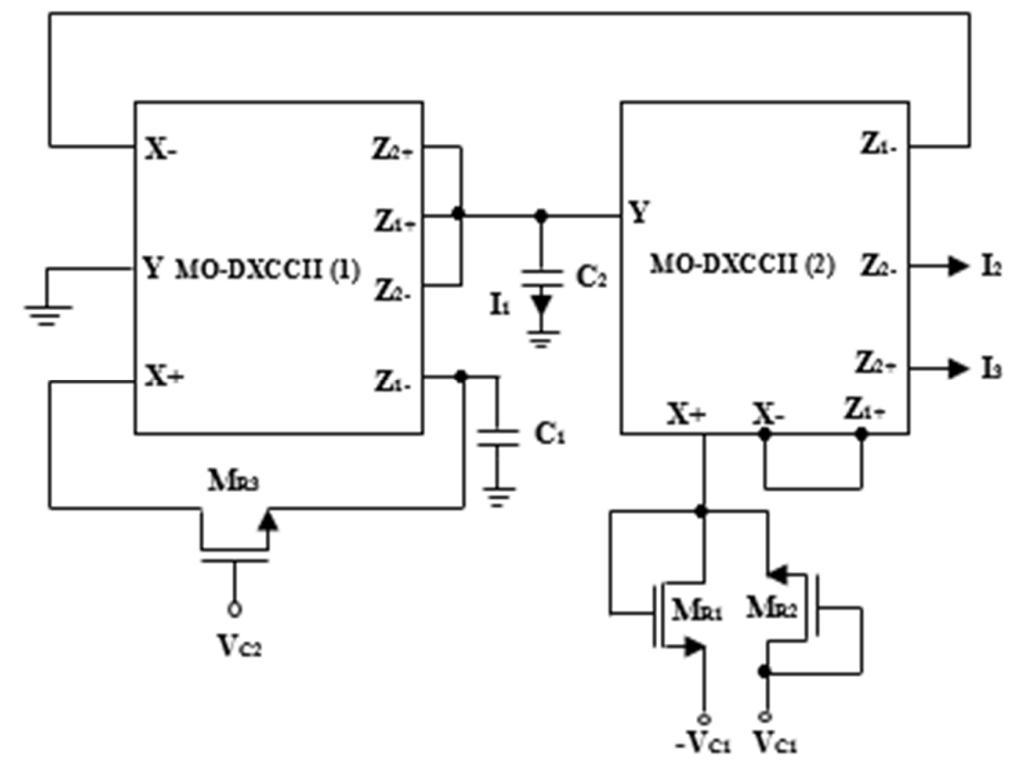

Figure9. Proposed resistorless circuit of CMQO

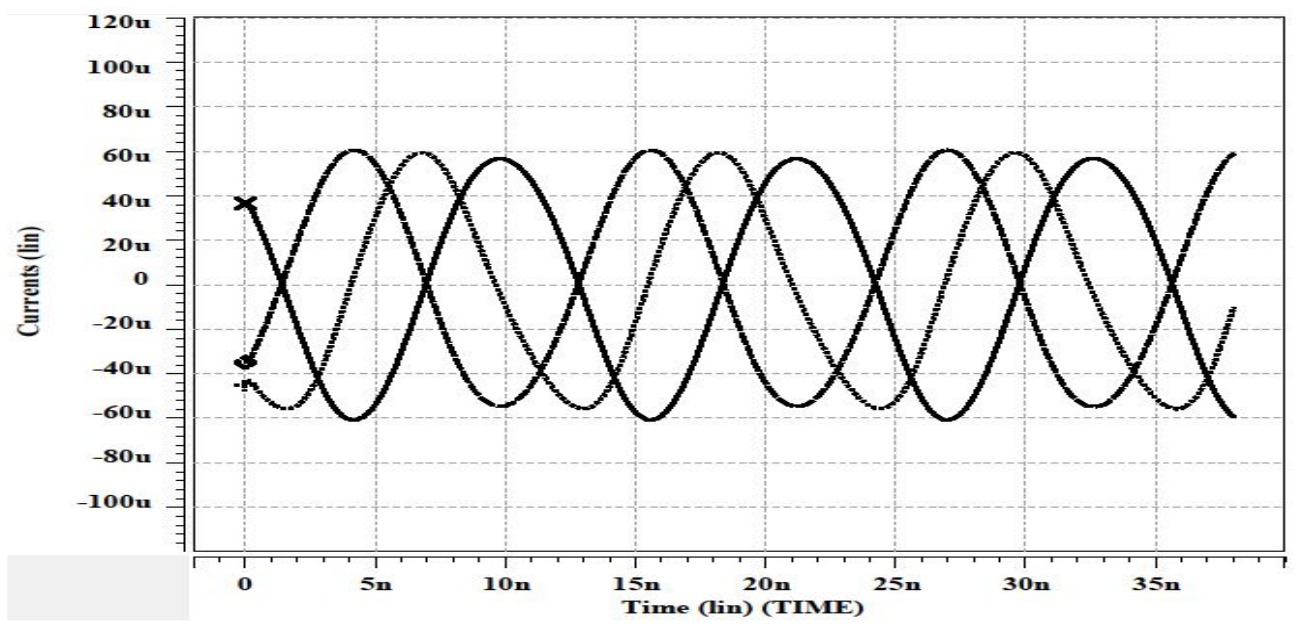

Figure10. Quadrature current output waveforms 


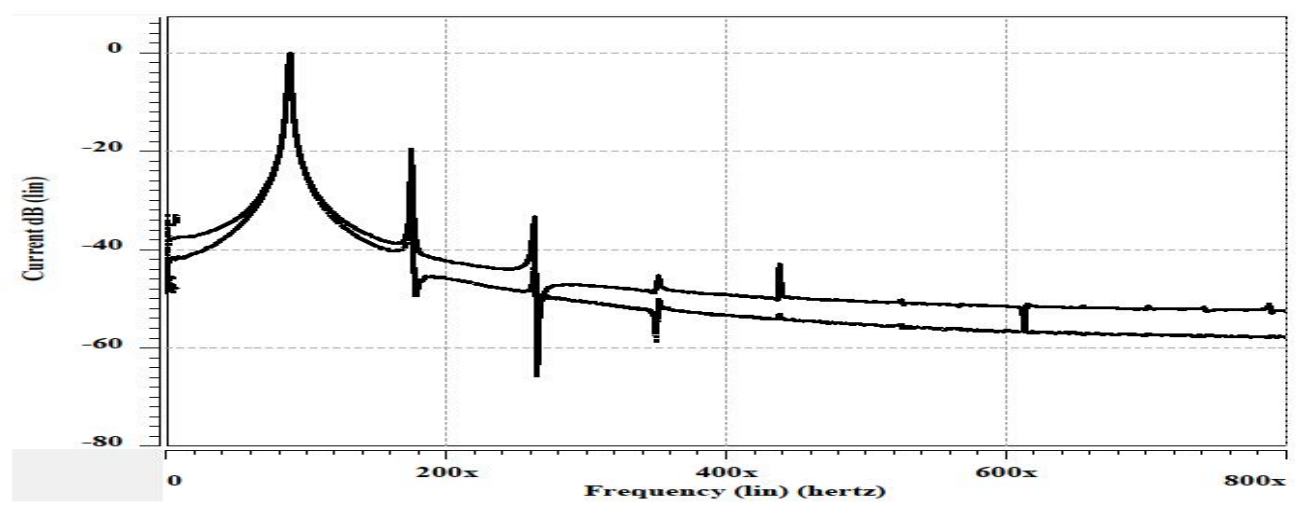

Figure11. Frequency spectrum of three current outputs

\section{CONCLUSION}

This paper presents a new CMQO based on two MO-DXCCIIs as active elements, two grounded capacitors and two resistors. The proposed circuit provides three quadrature current outputs simultaneously with high output impedances and each output exhibited low harmonic distortion. The proposed circuit also enjoys the low active and passive sensitivities. The performance of proposed circuit is quite good by keeping in view low operated voltage and high frequency of oscillation. This paper also includes the non-ideal and parasitic study of the proposed circuit of quadrature oscillator. Further, with the help of MOS based active resistors, the proposed circuit was made resistorless. HSPICE simulation results are given to confirm the theoretical analysis.

\section{ACKNOWLEDGEMENT}

The authors thank the Editor of AET-2015 for recommending this paper in the extended paper publication. The paper was submitted in the GRENZE Scientific Society's Journal, Grenze International Journal of Engineering and Technology (GIJET) as an extended paper publication, thus no charges were made for publishing this paper.

\section{REFERENCES}

[1] C. Toumazou, F. Lidjey, and D. Haigh, "Analog IC design: the current-mode approach", Peter Peregrinus, UK, 1990.

[2] S. Maheshwari, "Current-mode third-order quadrature oscillator", IET Circuits, Devices and Systems, vol. 4, no.3, 2010, pp. 188-195.

[3] S. Maheshwari, and I. A. Khan, "Current controlled third order quadrature oscillator", IEE Proceedings, Circuits, Devices and Systems, vol. 152, no. 6, 2006, pp. 605-607.

[4] S. N. Songkla, W. Jaikla, and B. Sreewirote, "A new resistor-less current-mode sinusoidal quadrature oscillator using CCCIIs", Proceedings of $18^{\text {th }}$ International Conference Mixed Design of Integrated Circuits and SystemsMIXDES, 2011, pp. 212-215.

[5] S. Maheshwari, and B. Chaturvedi, "High output impedance CMQOs using DVCCs and grounded components", International Journal of Circuit theory and Applications, vol. 39, no. 4, 2011, pp. 427-435.

[6] J. W. Horng, "Current-mode quadrature oscillator with grounded capacitors and resistors using two DVCCs", IEICE Transcations on Fundamentals of Electronics, Communications and Computer Science, vol. 86, no. 8, 2003, pp. 2152-2154.

[7] A. U. Keskin, and D. Biolek, "Current mode quadrature oscillator using current differencung transconductance amplifiers (CDTA)", IEE Proceedings, Circuits, Devices and Systems, vol. 153, no. 3, 2006, pp. 214-218.

[8] W. Jaikla, M. Siripruchyanun, J. bajer, and D. Biolek, "A simple current-mode quadrature oscillator using single CDTA", Radioengineering, vol. 17, no. 4, 2008, pp. 33-40.

[9] J. W. Horng, H. Lee, and J. Y. Wu, "Electronically tunable third-order quadrature oscillator using CDTAs", Radioengineering, vol. 19, no. 2, 2010, pp. 326-330.

[10] S. Chen, and J. Wang, "Current-mode current-tunable four phase quadrature oscillator", Optik-International Journal for Light and Electron Optics, vol. 125, no. 20, 2014, pp. 6227-6230. 
[11] A. U. Keskin, C. Aydin, E. Hancioglu, and C. Acar, "Quadrature oscillator using current differencing buffered amplifiers (CDBA)", Frequenz, vol. 60, no. 3-4, 2006, pp. 57-60.

[12] A. Lihiri, "Explicit-current output quadrature oscillator using second-generation current conveyor transconductance amplifier", Radioengineering, vol. 18, no. 4, 2009, pp. 522-526.

[13] S. Lawanwisut, and M. Siripruchyanun, "An active-only high-output impedance current-mode quadrature oscillator using CCCCTA based-lossless differentiatots", TENCON 2009-2009 IEEE Region 10 Conference, IEEE, 2009, pp. $1-4$.

[14] W. Sa-Ngiamvibool, and A. Jantakun, "Quadrature oscillator using CCCCTAs and grounded capacitors with amplitude controllability”, International Journal of Electronics, vol. 101, no. 12, 2014, pp. 1737-1758.

[15] W. Jaikla, and P. Prommee, "Electronically tunable current-mode multiphase sinusoidal oscillator employing CCCDTA-based allpass filters with only grounded passive elements," Radioengineering, vol. 20, no. 3, 2011, pp. 594-599.

[16] C. Sakul, W. Jaikla, and K. Dejhan, "New resistorless current-mode quadrature oscillators using 2 CCCDTAs and grounded capacitors," Radioengineering, vol. 20, no. 4, 2011, pp. 890-896.

[17] S. Maheshwari, and B. Chaturvedi, "High-input low-output impedance all-pass filters using one active element", IET Circuits, Devices and Systems, vol. 6, no. 2, 2012, pp. 103-110.

[18] P. Beg, M. A. Siddiqui, and M. S. Ansari, "Multi output filter and four phase sinusoidal oscillator using CMOS DXMOCCII", International Journal of Electronics, vol. 98, no. 9, 2011, pp. 1185-1198.

[19] J. Mohan, B. Chaturvedi, and S. Maheshwari, "Novel current-mode all-pass filter with minimum component count", International Journal of Image, Graphics and Signal Processing, vol. 5, no. 12, 2013, pp. 32-37.

[20] A. Zeki, and A. Toker, "The dual-X current conveyor (DXCCII): A new active device for tunable continous-time filters", International journal of Electronics, vol. 89, no. 12, 2002, pp. 913-923.

[21] A. Zeki, and A. Toker, "DXCCII-based tunable gyrator", AEU-International Journal of Electronics and Communications, vol. 59, no. 1, 2005, pp. 59-62.

[22] S. Minaei, and E. Yuce, "Unity/variable-gain voltage-mode/current-mode first-order all-pass filters using single dual-X second generation current conveyor", IETE Journal of Research, vol. 56, no. 6, 2010, pp. 305-312.

[23] Z. Wang, "2-MOSFET transresistor with extremely low distortion for output reaching supply voltages", Electronics Letters, vol. 26, no. 13, 1990, pp. 951-952. 